\title{
The Use of New Chemically Modified Cellulose for Heavy Metal Ion Adsorption and Antimicrobial Activities
}

\author{
R. Saravanan 1 , L. Ravikumar ${ }^{2 *}$ \\ ${ }^{1}$ KPR Institute of Engineering and Technology, Research and Development Centre, Bharathiar University, \\ Coimbatore, India \\ ${ }^{2}$ Department of Chemistry, C. B. M. College (Affiliated to Bharathiar University), Coimbatore, India \\ Email: ${ }^{*}$ ravikumarcbm@rediffmail.com
}

Received 22 February 2015; accepted 24 April 2015; published 27 April 2015

Copyright $@ 2015$ by authors and Scientific Research Publishing Inc.

This work is licensed under the Creative Commons Attribution International License (CC BY). http://creativecommons.org/licenses/by/4.0/

(c) ()

\section{Abstract}

A novel chemically modified cellulose (DTD) adsorbent bearing pendent methyl benzalaniline chelating group was synthesized. This new adsorbent was used for the removal of $\mathrm{Cu}^{2+}$ and $\mathrm{Pb}^{2+}$ heavy metal ions from aqueous solution. The chemical and structural characteristics of the adsorbent were determined using FT-IR, ${ }^{13} \mathrm{C}$ CP-MAS NMR, SEM, EDX and TGA analysis. The adsorption parameters, such as $\mathrm{pH}$, adsorbent dose, contact time, initial metal ion concentration and temperature were optimized. Adsorption kinetic parameters were fitted into pseudo-first-order and pseudo-second-order models. The kinetic data fitted well to the pseudo-second-order kinetic model. The adsorption isotherms such as Freundlich and Langmuir isotherms have been investigated. Thermodynamic parameters have also been evaluated. The negative values of $\Delta G^{0}$ and $\Delta H^{0}$ reveal that the adsorption system is spontaneous and exothermic in nature. The modified cellulose was challenged with microorganisms as a function of contact time. The biocidal results showed that the chemically modified cellulose has bactericidal effect against the bacterial species.

\section{Keywords}

\section{Modified Cellulose, Metal Ion Adsorption, Anti-Bacterial Activity}

\section{Introduction}

Heavy metal pollution has become a serious problem with the rapid increase of global industrial activities. In"Corresponding author. 
dustrial uses of metals and other domestic processes have introduced substantial amounts of potentially toxic heavy metals into the atmosphere and into the aquatic and terrestrial environments. The contamination of the aquatic systems with toxic heavy metal ions is a problem of global concern. Among the heavy metals, lead causes encephalopathy, cognitive impairment, behavioral disturbances, kidney damage, anemia and toxicity to the reproductive system [1]. The excessive copper concentrations can lead to weakness, lethargy and anorexia, as well as damage to the gastrointestinal tract [2]. Removal of copper and lead heavy metal ions from waste waters is essential from the standpoint of environmental pollution control. Numerous methods have been used to remove heavy metals from waste waters which principally include chemical precipitation, ion-exchange, reverse osmosis, coagulation and flocculation, membrane separation, biosorption, and adsorption [3].

In recent years, increasing costs and environmental considerations associated with the use of commercial adsorbents, have led to a significant body of research work aimed at developing new low-cost adsorbents derived from renewable resources. In this context, the advantages of using cellulose as the basis for new adsorbent design lie primarily in its high abundance, low cost and the relative ease with which it can be modified chemically [4]. Approaches to cellulose modification have been based on either direct chemical modification approaches [5]-[8] or the grafting of suitable polymer exchange to the cellulose back bone followed by fictionalizations [9]-[12].

Amongst all the treatment processes mentioned, adsorption using sorbents is one of the most popular and effective processes for the removal of heavy metals from waste water. The adsorption process offers flexibility in design and operation and in many cases produces treated effluent suitable for re-use, free of color and odor. In addition, because adsorption is sometimes reversible, the regeneration of the adsorbent with resultant economy of operation may be possible [13].

With the growing of public health awareness of disease transmissions and cross-infection caused by the microorganisms, the use of antimicrobial materials has been increased in many applications. The continuous search for potential antimicrobial agents has lead to identification of antimicrobial biomaterials that are based on polymers or their composites. In recent years, antibacterial textile fibers have gained an increasing attention because they offer several interesting properties. It could be either bactericidal (to kill bacteria) or bacteriostatic (to prevent the bacterial proliferation) and in the two cases it protects the human body [14]. Cellulose, which is a naturally occurring complex polysaccharide, is biodegradable and the most abundant renewable organic raw material at low costs in the world. Modification of cellulose by graft copolymerization and direct chemical modification techniques allows one to chemically change the cellulose chain by introducing functional groups, which leads to new cellulose products with new properties [15].

In this work, we report the chemical modification of cellulose using sodium metaperiodate $\left(\mathrm{NaIO}_{4}\right)$ oxidation followed by condensation with p-toluidine. The modified cellulose contains methyl formylimino groups which can both act as chelating group with metal ions and possess antimicrobial activities.

\section{Materials and Methods}

\subsection{Materials}

Cellulose (Loba), p-toluidine (Alfa Aesar), sodium metaperiodate (Sigma-Aldrich) was used as received. Copper and lead salts were procured from Sigma-Aldrich chemicals. All other chemicals and solvents used were either of analytical grades or purified according to standard procedures.

\subsection{Metal Solutions}

Metal salts $\mathrm{CuSO}_{4} \cdot 5 \mathrm{H}_{2} \mathrm{O}, \mathrm{Pb}\left(\mathrm{NO}_{3}\right)_{2}$ were used for preparing stock solutions. Stock solutions of $1000 \mathrm{mg} / \mathrm{L}$ of standardized $\mathrm{Cu}^{2+}, \mathrm{Pb}^{2+}$ ions were prepared by dissolving the exact amount of the salts in double distilled water. The stock solutions were diluted to the required experimental concentration for the batch adsorption experiments.

\subsection{Preparation of Chemically Modified Cellulose (DTD)}

The oxidation reaction using sodium metaperiodate was carried out onto cellulose before the coupling process. Sodium metaperiodate oxidation is a highly specific reaction that cleaves the bond between C2-C3 of the glucosidic ring and converts into the 2,3-dialdehydic groups, following the mechanism of Malaprade reaction, without significant side reactions [16] [17]. Cellulose powder suspended in distilled water was mixed with sodium me- 
taperiodate solution and stirred at room temperature in dark. After specified reaction time dialdehyde cellulose (DAC) formed was filtered and washed with deionised water until neutral conditions are achieved. During oxidation when the concentration of $\mathrm{NaIO}_{4}$ increases, the number of carbonyl groups per 100 glucose units also increases. To achieve approximately 30 carbonyl groups per 100 glucose units, the concentration of $\mathrm{NaIO}_{4}$ was kept at $0.04 \mathrm{M}$ with a reaction time of $4 \mathrm{hr}$ [18] [19]. The dialdehyde cellulose samples were dried under vacuum at room temperature to a constant weight. The C2-C3 dialdehyde groups of the cellulose are condensed with the aromatic amine p-toluidine to form the pendent Schiff bases in the cellulose chain. Typically $2 \mathrm{~g}$ of dialdehyde cellulose in double distilled water was stirred with $3 \mathrm{~g}$ of p-toluidine catalyzed by $\mathrm{HCl}$ at $70^{\circ} \mathrm{C}$ for $3 \mathrm{~h}$. The pale yellow color of dialdehyde cellulose slowly changes to reddish brown. At the end of the reaction period, chemically modified cellulose (DTD) was filtered, washed with hot water, ethanol and then dried under vacuum.

\subsection{Characterization Methods}

The heavy metal ion concentration of the solutions before and after equilibrium was determined by Atomic Absorption Spectrometer AA6300 (Shimadzu, Japan). The pH of solution was measured using a Hanna pH meter using glass electrode. FT-IR analysis was carried out using Shimadzu Spectrophotometer with KBr pellets. The SEM images of the DTD and metal loaded DTD were analyzed using a Leo Gemini1530 scanning electron microscope. Thermo gravimetric analysis (TGA) was recorded using a Perkin-Elmer analyzer in static air at a heating rate of $10^{\circ} \mathrm{C} / \mathrm{min}$. Solid-state ${ }^{13} \mathrm{C}$ CP-MAS NMR spectra were performed at $100.52 \mathrm{MHz}$ on a Bruker AMX-200 spectrometer.

\section{Adsorption Studies}

Batch adsorption experiments were carried out by shaking the flasks using a horizontal bench shaker (OrbitekTeqip-ACT/EQ/454) at $200 \mathrm{rpm}$. The experimental data obtained in batch studies were used to calculate the percentage removal of heavy metal ions by using mass balance equation.

$$
\text { \%Heavy metal ions removed }=\frac{C_{0}-C_{e}}{C_{0}} \times 100
$$

where $C_{0}$ and $C_{e}$ are initial and equilibrium final concentrations $(\mathrm{mg} / \mathrm{L})$ of the metal solutions respectively.

\subsection{Effect of Solution pH on Adsorption}

The effect of $\mathrm{pH}$ on the adsorption of DTD was carried out in the $\mathrm{pH}$ range of 2.0 to 10.0 at $30^{\circ} \mathrm{C}$. The samples were then shaken in a horizontal bench shaker at $200 \mathrm{rpm}$ at a different solution $\mathrm{pH}$ for $60 \mathrm{~min}$ and then filtered through Whatman 42 filter paper. The filtrate was analyzed using AASC.

\subsection{Effect of Adsorbent Dosage}

Batch adsorption experiments were carried out at different adsorbent dosages of DTD from 5 to $25 \mathrm{mg}$ at a pH of 6.0, by keeping the contact time and temperature constant.

\subsection{Effect of Contact Time}

Batch adsorption experiments were carried out by varying contact time of 20 - 120 min by keeping all other parameters constant.

\subsection{Effect of Metal Ion Concentration}

Initial metal ion concentrations were investigated in the range 50 to $300 \mathrm{mg} / \mathrm{L}$ at a $\mathrm{pH}$ 6.0.

\subsection{Adsorption Isotherms and Kinetics}

The adsorbed metal amount $q_{e}(\mathrm{mg} / \mathrm{g})$ was determined by using the following mass balance relationship:

$$
q_{e}=\frac{\left(C_{0}-C_{e}\right) V}{m} \times 100
$$


where $V$ is the volume of the solution (L); and $m$ is the adsorbent mass (g).

The amount of metal adsorbed at time $(t), q_{t}(\mathrm{mg} / \mathrm{g})$, was calculated using the following equation:

$$
q_{t}=\frac{\left(C_{0}-C_{t}\right) V}{m} \times 100
$$

$C_{t}$-the concentration of metal solution at any time $t(\mathrm{mg} / \mathrm{L})$.

\subsection{Antimicrobial Activity Test}

The antimicrobial activities of modified cellulose DTD against Escherichia coli, Staphylococcus aureus and Enterococcus faecalis were examined using the agar well diffusion assay method. Diluted bacterial cultures were spread on sterile Mueller-Hinton agar plates, after which modified cellulose (50 $\mu \mathrm{l})$ were placed on impregnated discs with $6 \mathrm{~mm}$ diameter for testing. The plates were incubated for $24 \mathrm{~h}$ at $37^{\circ} \mathrm{C}$ under aerobic conditions and the diameter of the inhibition zones of each disc were measured and recorded [20].

\section{Results and Discussion}

\subsection{Characterization}

Synthesis of chemically modified cellulose containing pendent methoxy benzalanilene group in the polymer chain is presented in Figure 1. The reaction involved a nucleophilic addition of the amino group to the cellulose dialdehyde carbonyl followed by an acid catalyzed dehydration.

The FTIR spectra of native cellulose (RA) and DTD are presented in Figure 2. The IR spectrum of cellulose exibited the main characterisict cellulose peaks. Absorbence at $3348 \mathrm{~cm}^{-1}$ (-OH strecthing), $2903 \mathrm{~cm}^{-1}$ (C-H stretching), $1664 \mathrm{~cm}^{-1}$ (C-C ring stretching and -OH in plane bending), $1430 \mathrm{~cm}^{-1}$ (- $-\mathrm{CH}_{2}$ bending), $1371 \mathrm{~cm}^{-1}$ (-CH bending) and $1058 \mathrm{~cm}^{-1}$ (C-O-C stretching) are in good agreement with the reported values. In the chemically modified cellulose the -OH stretching frequency appeared at $3345 \mathrm{~cm}^{-1}$ while that of the imine -CH stretching frequency appeared at $2903 \mathrm{~cm}^{-1}$. On oxidation with $\mathrm{NaIO}_{4}$ the pyranose ring is cleaved at $\mathrm{C} 2-\mathrm{C} 3$ and

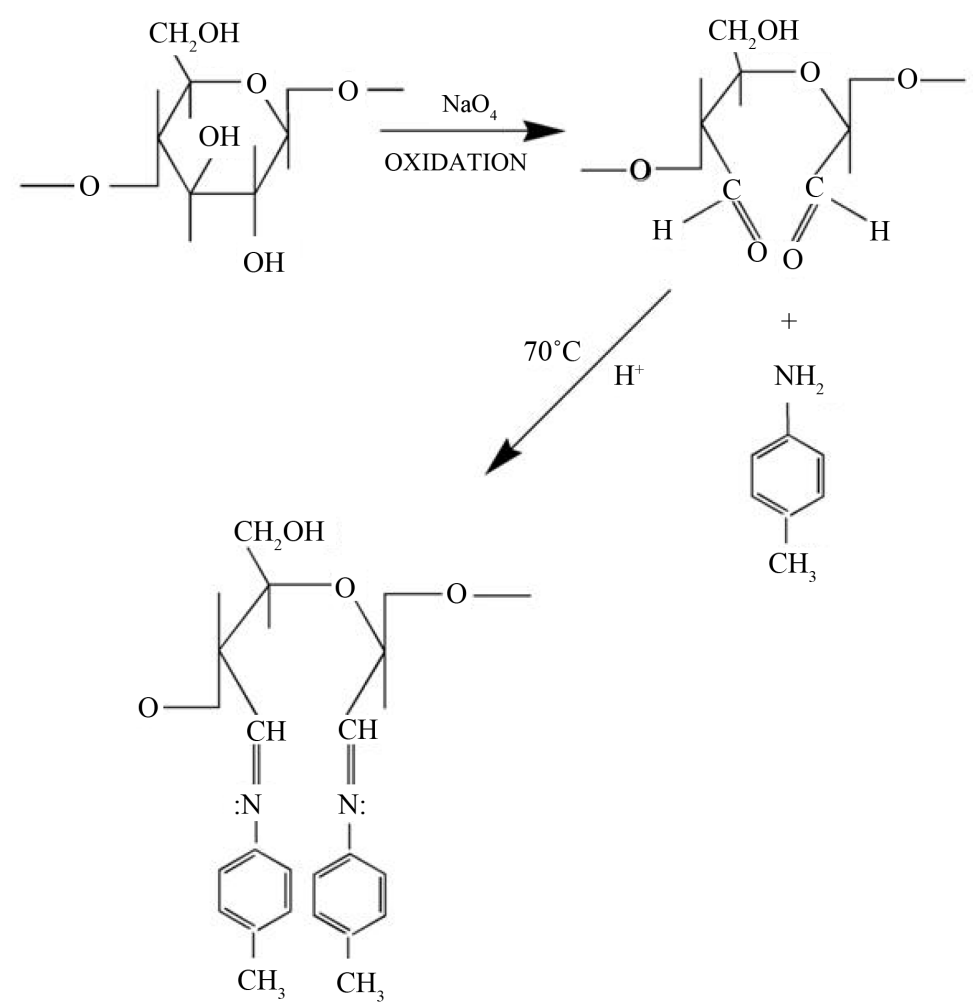

Figure 1. Synthesis of chemically modified cellulose. 


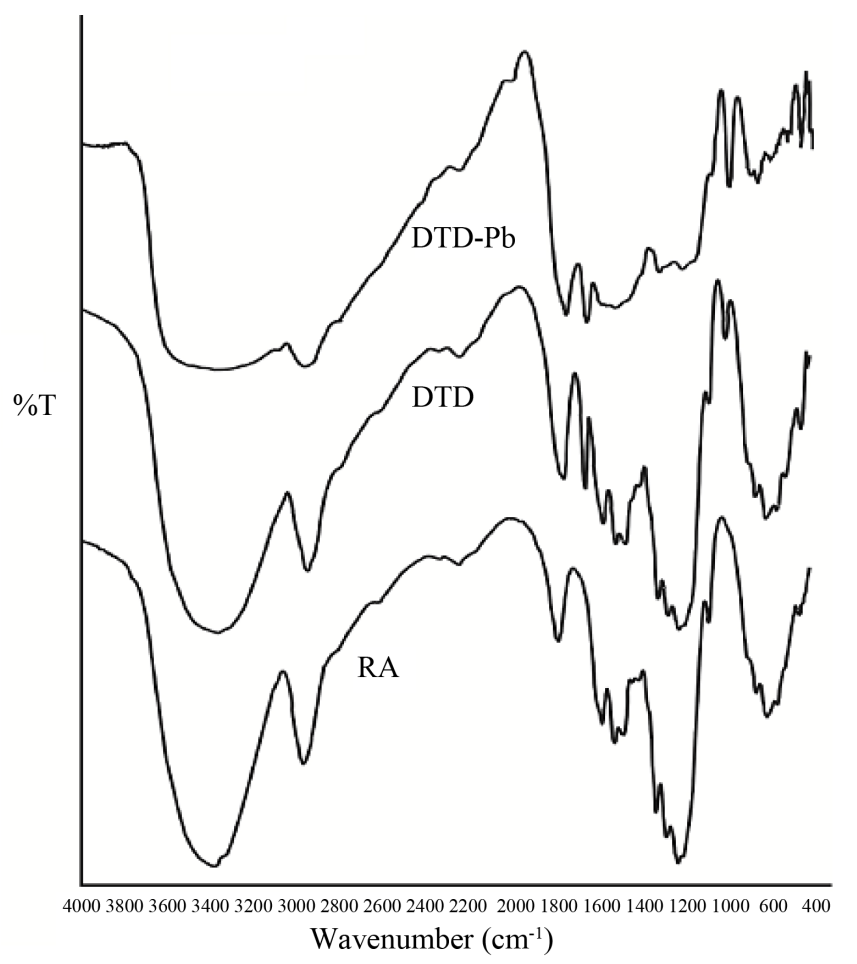

Figure 2. FT-IR spectra of native cellulose (RA), chemically modified cellulose (DTD) and $\mathrm{Pb}^{2+}$ metal ion adsorbed modified cellulose DTD-Pb.

hence the C-C ring stretching frequency is not observed in the modified cellulose. A new peak at $1624 \mathrm{~cm}^{-1}$ is clearely due to the $-\mathrm{N}=\mathrm{CH}$ - stretching frequency and the $\mathrm{C}-\mathrm{N}$ stretching frequency appeared at $1517 \mathrm{~cm}^{-1}$ which supports the formation of methyl benzalaniline pendent groups in the chemically modified cellulose. To further establish the structure of chemically modified cellulose, solid state ${ }^{13} \mathrm{C}-\mathrm{NMR}$ spectroscopy was performed on both native and modified cellulose. ${ }^{13} \mathrm{C}$ CP-MAS NMR spectra of natural cellulose and DTD are given in Figure 3 and Figure 4, respectively. In natural cellulose the C1-C6 signals appeared between $\delta$ values of 62.4 $102.4 \mathrm{ppm}$. However, chemically modified cellulose DTD clearly showed the presence of pendent methyl benzalaniline groups in the cellulose chain (Figure 4). Apart from the usual signals, broad signals at $201.7 \mathrm{ppm}$ are due to the azomethine carbon C7. Aromatic carbons C8 appeared at 175.9 ppm, C9 and C10 showed signal at $126.8 \mathrm{ppm}$ and $151.1 \mathrm{ppm}$ respectively. The $\mathrm{C} 11$ of $\mathrm{CH}_{3}$ groups appeared at $18.1 \mathrm{ppm}$.

\subsection{Thermal Stability}

TG traces of cellulose and DTD are shown in Figure 5. It is clear from the figure that natural cellulose has better thermal stability than chemically modified cellulose DTD. Initial decomposition temperatures of natural cellulose and DTD occur around $270^{\circ} \mathrm{C}$ and $150^{\circ} \mathrm{C}$ respectively. This indicates that DTD can be used as an adsorbent up to $150^{\circ} \mathrm{C}$. The decrease in thermal stability of DTD is probably due to the breaking up of pyranose ring at $\mathrm{C} 2$ and $\mathrm{C} 3$.

\subsection{Metal Ions Uptake Studies}

\subsubsection{SEM Analysis}

Scanning electron micrographs of DTD and metal loaded DTD are shown in Figures 6(a)-(c). Modified cellulose (DTD) surface is more irregular, rough and has open porous structure. The presence of pores in DTD suggests the possibility of the metal ions to be trapped and adsorbed onto the surface. These cavities are large enough to allow the metal ions to penetrate into the surface, and interact therein with the surface chelating groups. Surface morphology of the metal ion adsorbed DTD shows layers of metal ions on to porus surface. The 


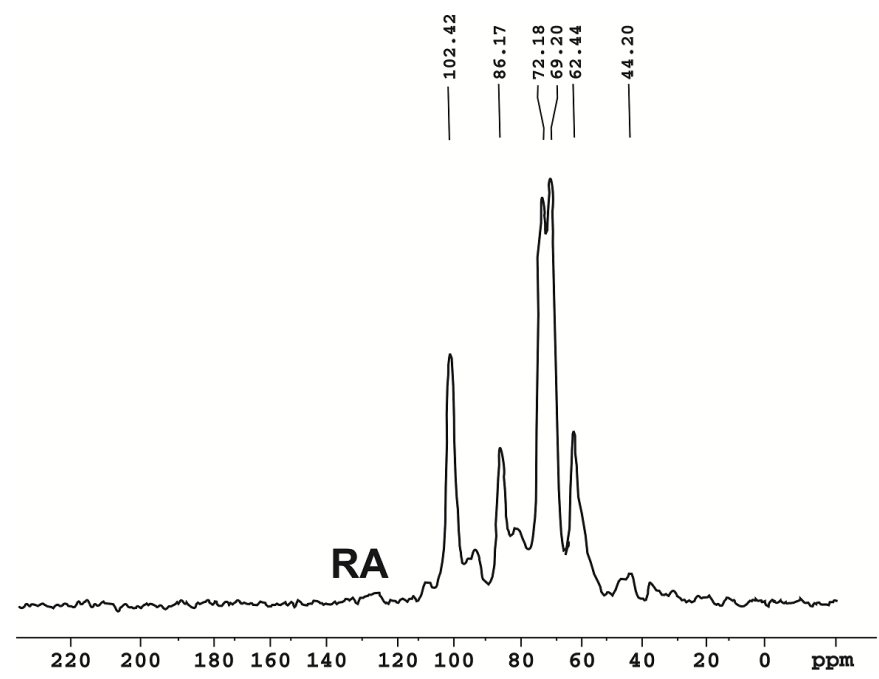

Figure $3 .{ }^{13} \mathrm{C}$ CP-MAS NMR spectrum of native cellulose.

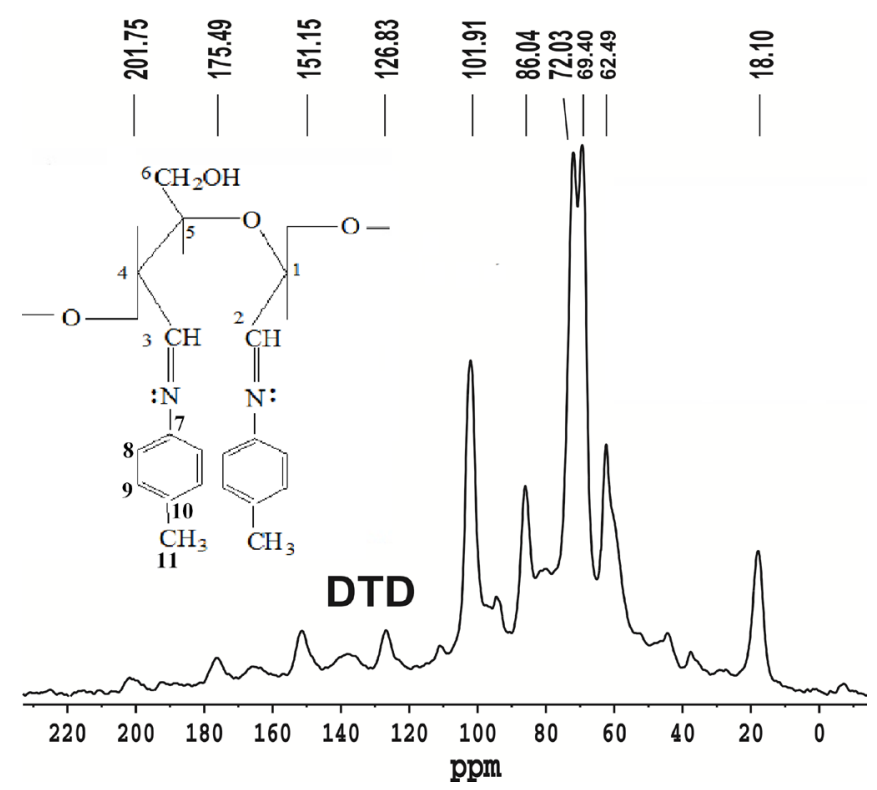

Figure $4 .{ }^{13} \mathrm{C}$ CP-MAS NMR spectrum of DTD.

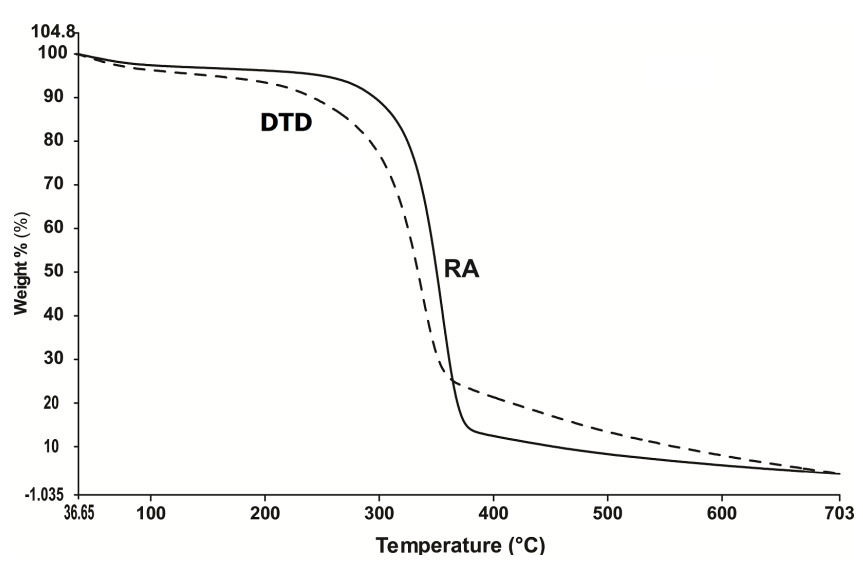

Figure 5. TG traces of natural cellulose and DTD. 


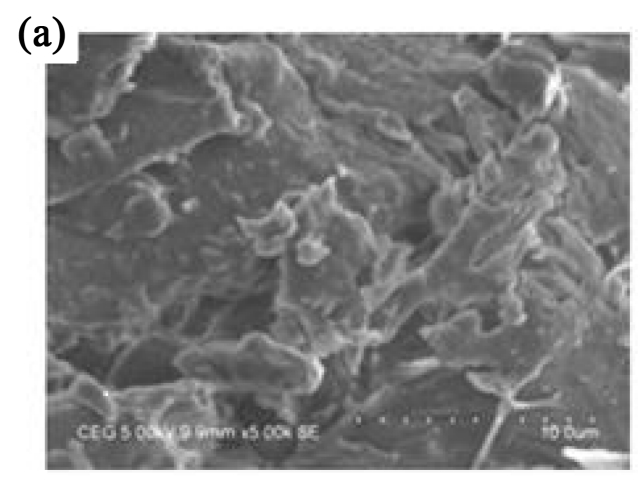

(b)

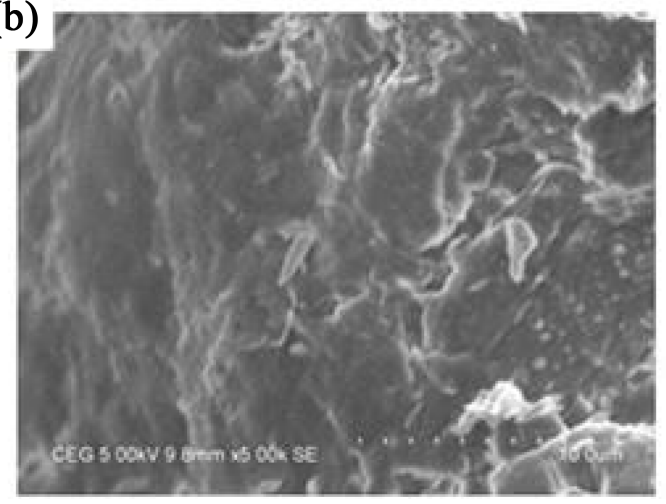

(c)

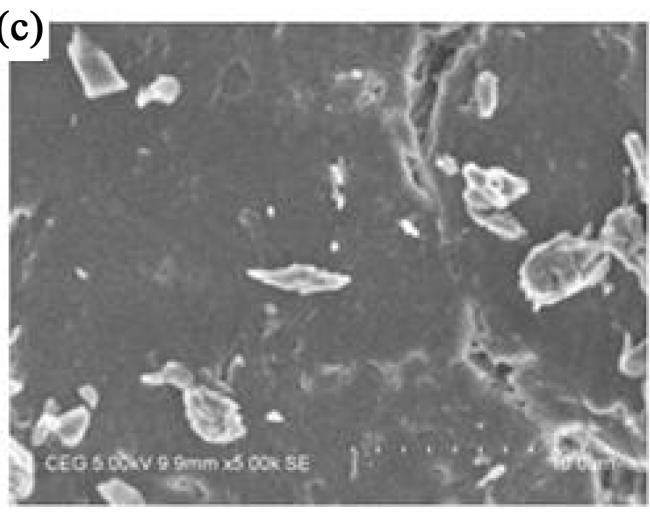

Figure 6. Scanning electron micrographs of (a) DTD, (b) $\mathrm{Pb}^{2+}$ loaded DTD and (c) $\mathrm{Cu}^{2+}$ adsorbed DTD.

particle size was measured by particle size analyser and was found to be $448.3 \mathrm{~nm}$. The value of the average particle size of the adsorbent provides more surface area for the removal of $\mathrm{Cu}^{2+}$ and $\mathrm{Pb}^{2+}$ ions from the aqueous media.

Figure 7 present the EDX spectra of DTD, $\mathrm{Cu}^{2+}$ treated DTD and $\mathrm{Pb}^{2+}$ treated DTD respectively. It is obvious that the DTD spectrum (Figure 7(DTD)) showed only carbon, oxygen and nitrogen peaks. However, $\mathrm{Cu}^{2+}$ and $\mathrm{Pb}^{2+}$ metal ion solution treated DTD (Figure 7(DTD-Cu) \& Figure 7(DTD-Pb)) showed in addition to C, O and $\mathrm{N}$ clear peaks for $\mathrm{Cu}$ and $\mathrm{Pb}$, thus confirming the metal ion uptake ability of DTD from aquous solutions.

\subsubsection{Influence of Initial pH Value}

The $\mathrm{pH}$ of the solution affects the adsorptive process through protonation and deprotonation of functional groups of the active sites of the adsorbent surface. Initial $\mathrm{pH}$ values were varied from 2 - 10 and the corresponding \% adsorption is given in Figure 8. The adsorption capacity increases with increasing $\mathrm{pH}$ values up to 6 and decreases beyond this value. The present removal of metal ions exhibited a significant increase at $\mathrm{pH} 6$ is attributed to the low $\mathrm{H}^{+}$concentration which may compete with metal ions for coordination with active azomethine groups and subsequently lower the percent removal at low $\mathrm{pH}$ values. However at a lower $\mathrm{pH}$ value of 2 the percent removal of metal ions is $>70 \%$ which suggests that the adsorbent is an effective one even at lower $\mathrm{pH}$ values which is an important requirement in the industrial applications.

\subsubsection{Effect of Adsorbent Dose}

Adsorbent dose was varied from $5 \mathrm{mg}-25 \mathrm{mg}$ and the percent removal is shown in Figure 9. As the adsorbent dose increases the percent removal of metal ion increases and reaches a saturated value at the dosage of $20 \mathrm{mg}$. With increase in the adsorbent dose, the active sites available for coordination with metal ion increases and hence the percent removal increases. At $20 \mathrm{mg}$ dosage maximum metal ions are removed and any further increase beyond this value, the percent removal remains constant. One of the interesting aspects of this study is that even at a low dosage of the adsorbent $(10 \mathrm{mg}$ ) the percent removal is $>70 \%$ suggesting the high concentra- 


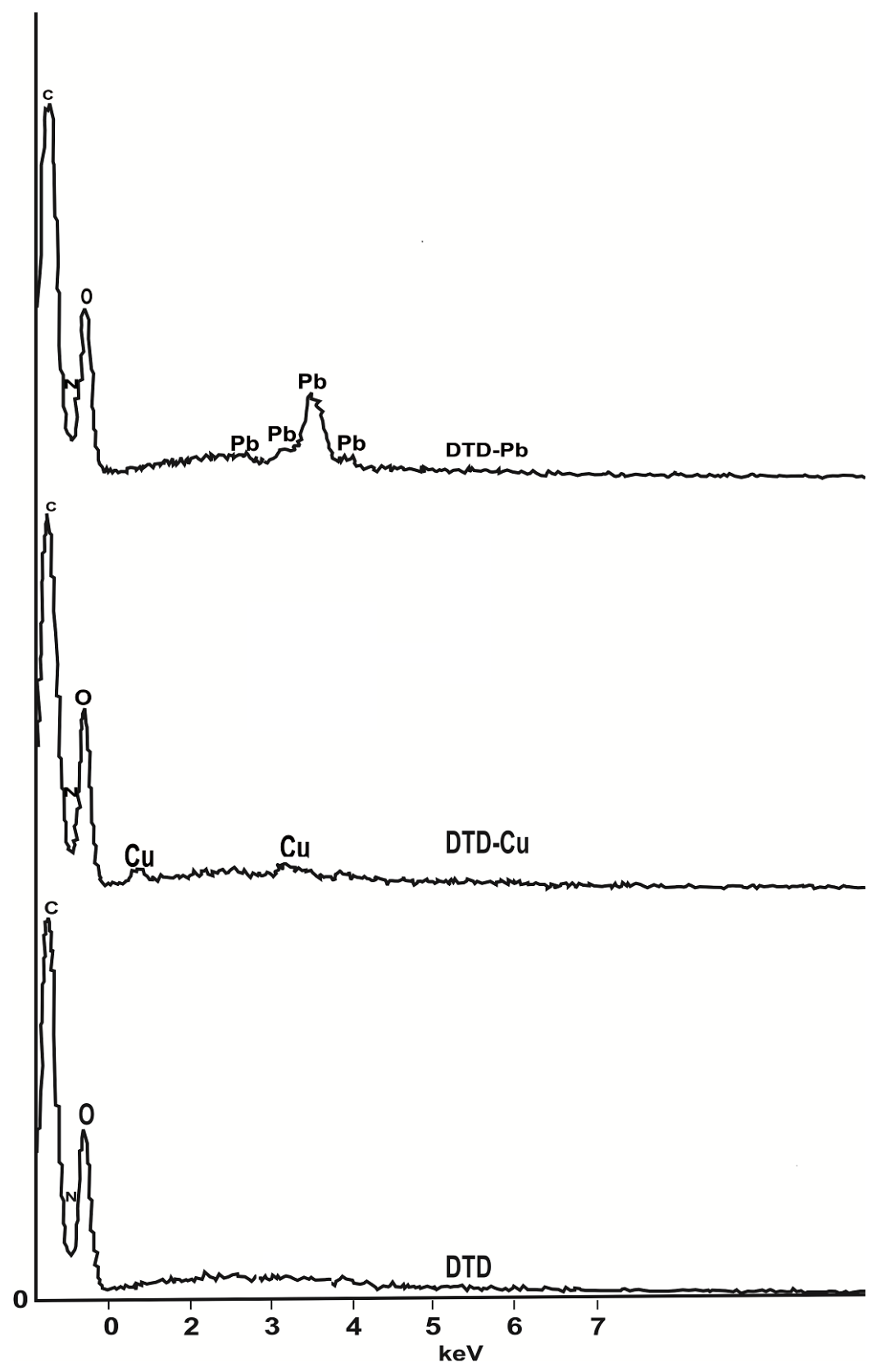

Figure 7. EDX spectra of DTD, $\mathrm{Cu}^{2+}$ treated DTD and $\mathrm{Pb}^{2+}$ treated DTD.

tion of the coordinating sites in the cellulose chain.

\subsubsection{Adsorption Isotherms}

The initial concentration of metal ions is an important factor for effective adsorption. The percentage removal of metal ions $\mathrm{Cu}(\mathrm{II}), \mathrm{Pb}(\mathrm{II})$ at different metal ion concentration $(10-30 \mathrm{mg} / \mathrm{L})$ were performed by keeping all other parameters constant. An adsorption isotherm can be used to characterize interaction of the adsorbates with adsorbents and optimizing the use of adsorbents. Adsorption isotherms are the basic requirements for designing any adsorption system. The distribution of metal ions between the liquid phase and the adsorbent is a measure of the position of equilibrium in the adsorption process and can be expressed by a series of isotherm models. The non-linear forms of the Langmuir [21] and Freundlich [22] adsorption isotherm models were used to evaluate the adsorption experimental data, using MATLAB R2009a. The non-linear forms of the Langmuir and Freun- 
Effect of $\mathrm{pH}$

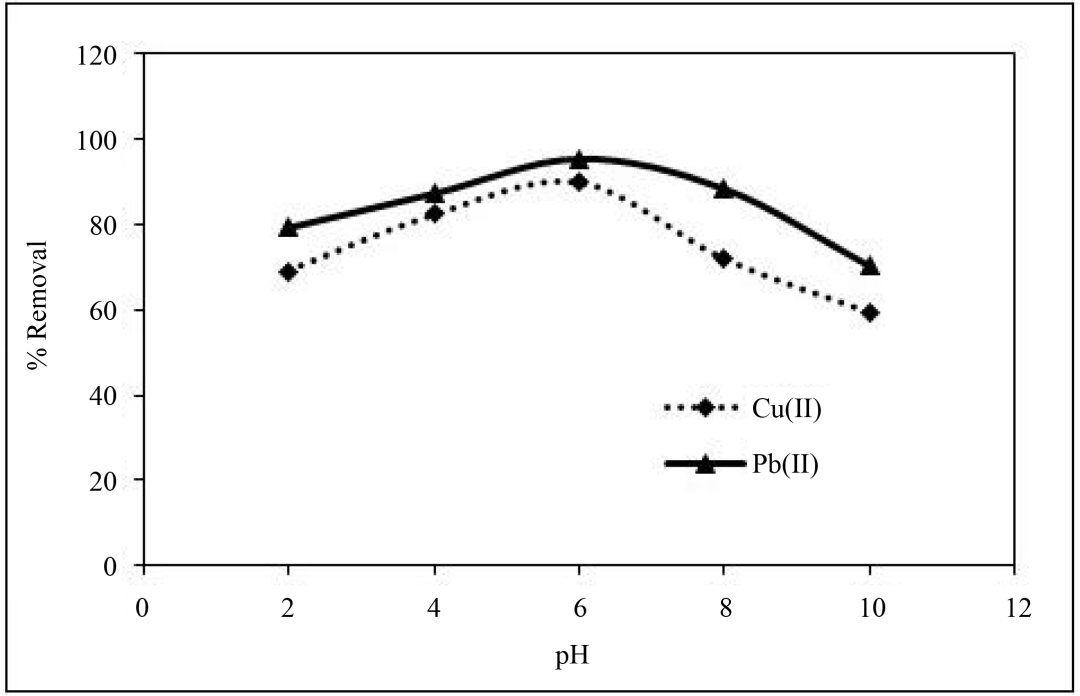

Figure 8. Effet of initial pH values on adsorption efficiency.

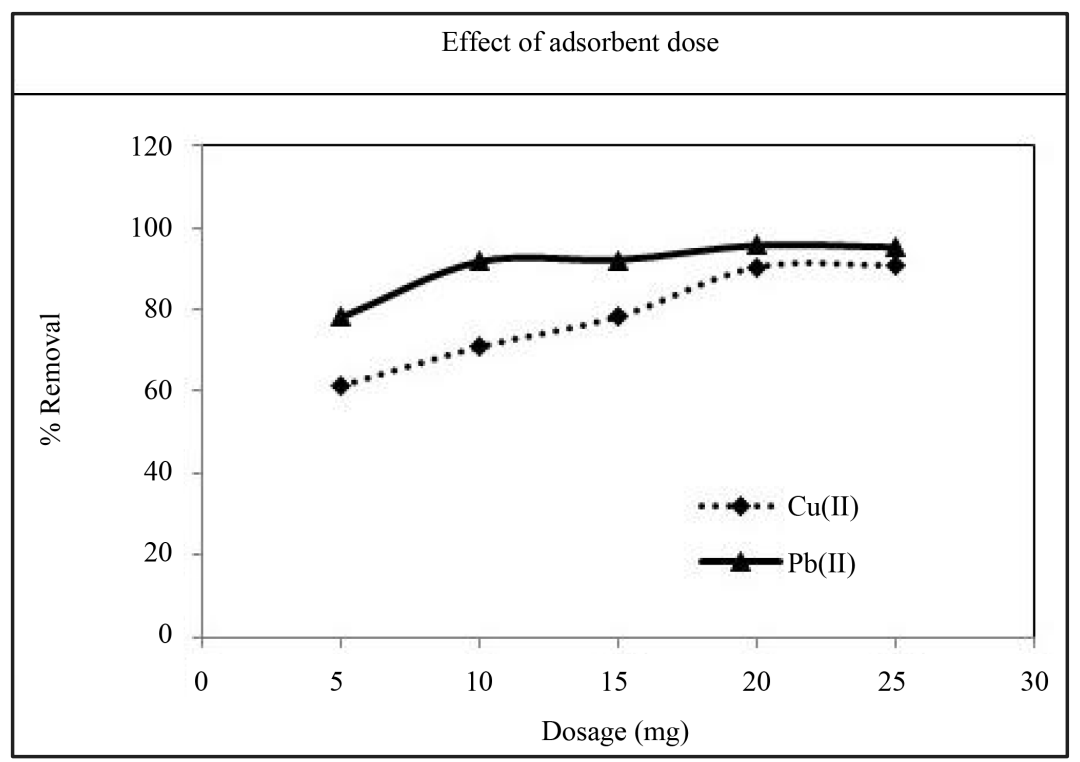

Figure 9. Effect of adsorbent dose on percentage removal.

dlich adsorption isotherms based on experimental observations are given in Figure 10.

\subsubsection{Langmuir Isotherm Model}

Langmuir isotherm models the monolayer coverage of adsorption surface. This model assumes that the maximum adsorption occurs at specific structurally homogeneous adsorption sites within the adsorbent and intermolecular forces decreases rapidly with the distance from adsorption surface. The non-linear equation of Langmuir isotherm model is expressed as;

$$
q_{e}=\frac{q_{m} K_{L} C_{e}}{1+K_{L} C_{e}}
$$

where $C_{e}$-the equilibrium concentration of the metal ions in the solution (mg/L), $q_{e}$-the adsorbed value of the metal ion at equilibrium concentration (mg/g), $q_{m}$-the maximum adsorption capacity (mg/g) and $K_{L}$ is the 
Non linear adsorption isotherm for Cu(II) adsorption onto DTD

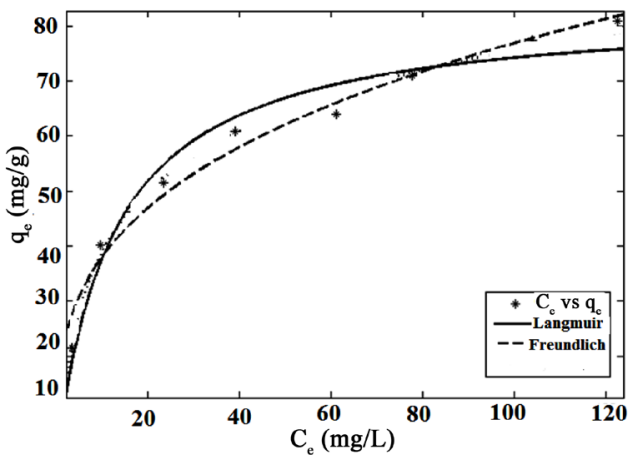

Non linear adsorption isotherm for Pb(II) adsorption onto DTD

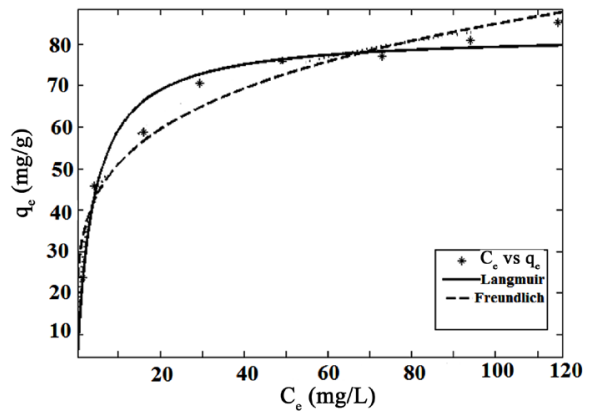

Figure 10. Adsorption isotherms.

Langmuir binding constant which is related to the energy of adsorption. The data obtained $q_{e}, K_{L}$ and correlation coefficient $\left(R^{2}\right)$ values are shown in Table 1 . The suitability of the adsorption process could be evaluated by calculating the separation factor constant $\left(R_{L}\right): R_{L}>1.0$. unsuitable; $R_{L}=1.0$. linear; $0<R_{L}<1$, suitable; $R_{L}=0$, irreversible. The $R_{L}$ value can be calculated from the following equation.

$$
R_{L}=\frac{1}{1+b C_{o}}
$$

where $b$-the Langmuir adsorption equilibrium constant and $C_{o}$ - the initial metal ion concentration. The values of $R_{L}$ lie between 0.0081 and 0.0069 , indicating suitability of the chemically modified cellulose as adsorbent for $\mathrm{Cu}(\mathrm{II})$ and $\mathrm{Pb}(\mathrm{II})$ from aqueous solution.

\subsubsection{Freundlich Isotherm Model}

The Freundlich isotherm model is related to multilayer adsorption, heterogeneous surface and interaction between adsorbed molecules. The nonlinear form of the Freundlich equation is given by

$$
K_{f} q_{e}=C_{e}^{1 / n}
$$

where $K_{f}$-the Freundlich constant $\left((\mathrm{mg} / \mathrm{g})(\mathrm{L} / \mathrm{mg})^{1 / 2}\right)$ which represents the adsorption capacity and the strength of the adsorption bond and $n$-the heterogeneity factor which represents the bond distribution. The values of $n$, between 1 and 10 indicate favorable adsorption. In the present study, the $n$ value of DTD adsorbent-metal ion system of $\mathrm{Cu}^{+2}$ (3.60) and $\mathrm{Pb}^{+2}$ (3.74) was found to be greater than 1 , which indicates that the adsorption system is a favorable one and suggesting physical adsorption. According to the correlation coefficients, the experimental results exhibited the best fit with Langmuir model suggesting a mono layer homogeneous adsorption of the metal ions on to the chemically modified cellulose chelating DTD. The maximum adsorption capacity of $\mathrm{Cu}(\mathrm{II})$ and $\mathrm{Pb}(\mathrm{II})$ metal ions were found to be 157.3 and $153.5 \mathrm{mg} / \mathrm{g}$, respectively, indicating the high potentiality of the adsorbent DTD.

The adsorption capacity of the present DTD adsorbent has been compared with other adsorbents reported for copper and lead. 


\begin{tabular}{|c|c|c|c|}
\hline \multirow{2}{*}{ Adsorbent } & \multicolumn{3}{|c|}{ Adsorption capacity (mg/g) } \\
\hline & $\mathrm{Cu}^{2+}$ ion & $\mathrm{Pb}^{2+}$ ion & References \\
\hline Aniline formaldehyde coated & 76.3 & - & {$[23]$} \\
\hline Tree fern & 11.7 & - & {$[24]$} \\
\hline Grafted silica & 16.5 & - & {$[25]$} \\
\hline Dye loaded sawdust & 9.8 & 17.90 & {$[26]$} \\
\hline $\mathrm{HCl}$ treated clay & 80.90 & 63.20 & [27] \\
\hline Cork biomass & 44.60 & 22.22 & {$[28]$} \\
\hline p-tert(dimethylamino)methyl-calix[4]arene & 52.80 & 36.40 & [29] \\
\hline Modified coir fibers & 4.33 & 7.88 & {$[30]$} \\
\hline Green algae spirogyra & 133.0 & - & [31] \\
\hline Succinylatedmercericed cellulose (DIPCI) & 56.8 & 147.1 & [32] \\
\hline Hyperbranched aliphatic polyester grafted cellulose & 9.8 & - & [33] \\
\hline Vinyl pyrrolidone grafted cellulose & - & 323 & [34] \\
\hline Poly(hydroethyl acrylate)-Grafted cross-linked poly(vinyl chloride) & 55 & - & [35] \\
\hline Cellulose modified with azomethine (DTD) & 157.3 & 153.5 & Present work \\
\hline
\end{tabular}

Table 1. Isotherm parameters for the adsorption of $\mathrm{Pb}^{2+}$ and $\mathrm{Cu}^{2+}$ over DTD.

\begin{tabular}{cccc}
\hline Isotherm model & Parameters & $\mathbf{C u}^{2+}$ ion & $\mathbf{P b}^{2+}$ ion \\
\hline & $K(\mathrm{~L} / \mathrm{mg})$ & 0.0737 & 0.0962 \\
Langmuir & $q_{m}(\mathrm{mg} / \mathrm{g})$ & 157.3 & 153.5 \\
& $R^{2}$ & 0.9686 & 0.9763 \\
& & 38.05 & 41.1 \\
Freudlich & $K_{f}(\mathrm{mg} / \mathrm{g})$ & 3.6 & 3.74 \\
& $n$ & 0.8032 & 0.9675 \\
\hline
\end{tabular}

When compared to other cellulose based adsorbents, the present chemically modified adsorbent is a highly efficient one for the removal of $\mathrm{Pb}^{2+}$ and $\mathrm{Cu}^{2+}$ ions from aqueous solution.

\subsubsection{Kinetic Studies}

Adsorption kinetics provides valuable information about the controlling mechanism of the adsorption process, rate of the adsorbate uptake and optimum operating conditions for the full-scale batch process. Adsorption kinetic models, such as the pseudo-first-order [36] and pseudo-second-order [37] models were used for the experimental data.

The effect of adsorption time on the removal of $\mathrm{Pb}^{2+}$ and $\mathrm{Cu}^{2+}$ by modified chelating DTD is presented in Figure 11. As can be seen, the removal showed a rapid rate for the first $60 \mathrm{~min}$ where the percent removal reached about $93 \%$ and $90 \%$ for $\mathrm{Pb}^{2+}$ and $\mathrm{Cu}^{2+}$ respectively.

For better understanding of the kinetic mechanism which governs the whole process, the experimental data obtained were fitted with the well known kinetic pseudo-first-order and pseudo-second-order models according to the following equations:

$$
1 / q_{t}=k_{i} / q_{e t}+1 / q_{e}
$$

where $k_{i}$ is the pseudo-first-order rate constant $\left(\mathrm{min}^{-1}\right)$ of adsorption and $q_{e}$ and $q_{t}(\mathrm{mg} / \mathrm{g})$ are the amounts of 


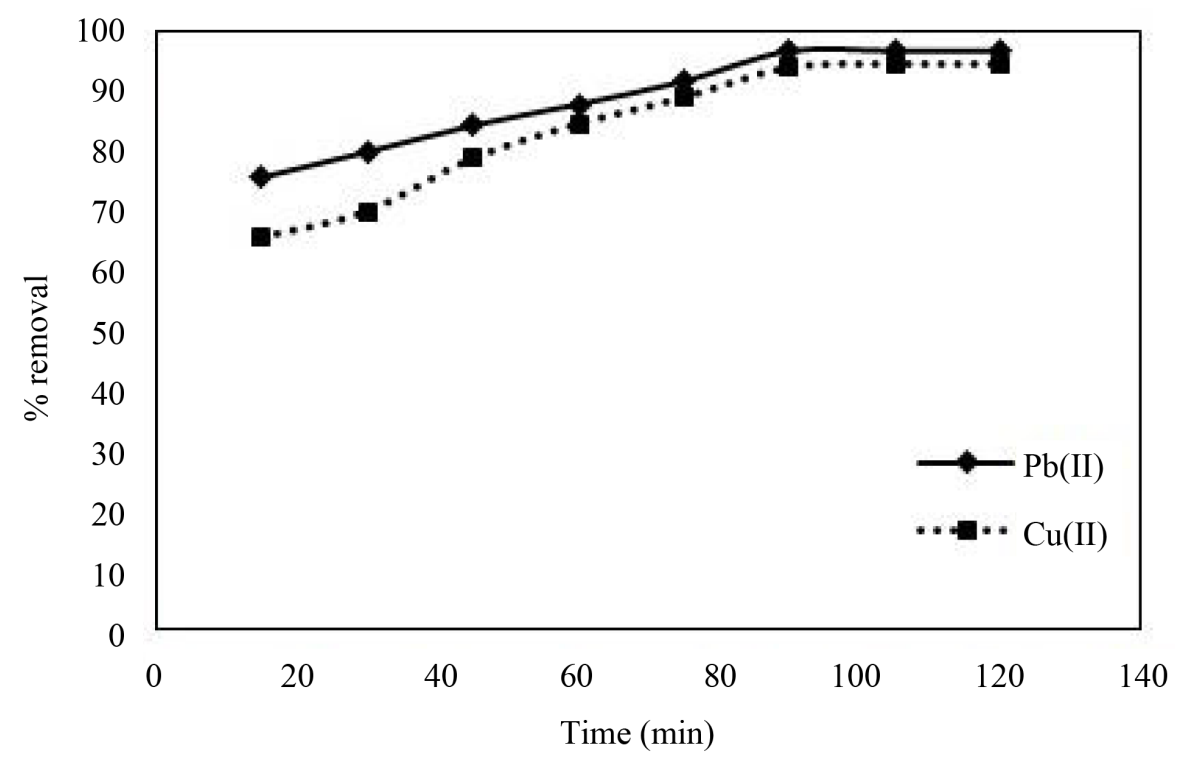

Figure 11. Effect of contact time on percentage removal.

metal ion adsorbed at equilibrium and time $t(\mathrm{~min})$ respectively. The linear form of pseudo-second-order equation can be written as

$$
t / q_{t}=1 / k_{2} q_{e}^{2}+\left(1 / q_{e}\right) t
$$

where $k_{2}$ is the pseudo-second order rate constant of adsorption (g/(mg $\left.\cdot \mathrm{min}\right)$ ).

All the kinetic parameters of the removal process are summarized in Table 2. As can be seen the correlation coefficients $\left(R^{2}\right)$, the experimental data exhibited the best fit with the pseudo-second-order kinetic model. This indicates that the chemical coordination step is considered as the rate determining step without the involvement of a mass transfer in solution [38] [39]. The modified cellulose DTD is characterized for its high concentration of the pendent methyl benzalaniline groups, which contains azomethine moieties which can act as Lewis base on coordinating with heavy metal ions.

\subsubsection{Adsorption Thermodynamics}

The thermodynamic studies were conducted at various temperatures (300 - $335 \mathrm{~K}$ ). It provides information on energetic changes that are associated with adsorption and adsorption process is spontaneous or not. The thermodynamic parameters for the adsorption including the Gibbs free energy change $\left(\Delta G^{0}\right)$, the enthalpy change $\left(\Delta H^{0}\right)$, and the entropy change $\left(\Delta S^{0}\right)$, were calculated using the following equations,

$$
\Delta G=-R T \ln K \Delta G=\Delta H-T \Delta S
$$

where $\Delta G^{0}$-standard free energy changes ( $\mathrm{J} / \mathrm{mol}$ ), $R$ is the universal gas constant $8.314 \mathrm{~J} / \mathrm{mol} / \mathrm{K}$ and $T$ is the absolute temperature, respectively. $\Delta G^{0}$ was calculated and $\Delta H^{0}$ and $\Delta S^{0}$ were obtained from the slope and intercept of the plot $\log K$ versus $1 / T$. The values of $\Delta G^{0}, \Delta H^{0}$ and $\Delta S^{0}$ for the adsorption onto DTD are given in Table 3. The negative values of $\Delta G^{0}$ at all temperatures and $\Delta H^{0}$ indicates that metal-DTD adsorption system is a spontaneous and exothermic in nature. The change of Gibbs free energy decreased with increasing temperature indicates a more efficient adsorption has occurred at higher temperatures. The negative entropy $\left(\Delta S^{0}\right)$ of adsorption confirms the decreased randomness at the solid-solution interface during adsorption which reflects the affinity of the adsorbent (DTD) toward metal ions.

\subsubsection{Desorption Studies}

A most important problem is the recyclability of adsorbent and multi-usability. The regenerated adsorbent was used up to five adsorption-desorption cycles with $\mathrm{Cu}(\mathrm{II})$ and $\mathrm{Pb}(\mathrm{II})$ ions and the results are given in Figure 12. 
Table 2. Kinetic parameters of removal of $\mathrm{Cu}$ and $\mathrm{Pb}$ onto DTD.

\begin{tabular}{cccc}
\hline Kinetic Model & Parameters & $\mathbf{P b}^{\mathbf{2 +}}$ ion & $\mathbf{C u}^{2+}$ ion \\
\hline \multirow{3}{*}{ Pseudo-first order } & $k_{a d}\left(\mathrm{~min}^{-1}\right)$ & 0.059 & 0.023 \\
& $q_{e}, \mathrm{cal}(\mathrm{mg} / \mathrm{g})$ & 62.08 & 26.12 \\
& $\mathrm{R}^{2}$ & $\mathbf{0 . 8 3 6}$ & $\mathbf{0 . 9 5 8}$ \\
& $q_{e}, \mathrm{cal}(\mathrm{mg} / \mathrm{g})$ & 52.63 & 52.63 \\
Pseudo-second order & $k\left(\mathrm{~g} \cdot \mathrm{mg}^{-1} \cdot \mathrm{min}^{-1}\right)$ & $2.23 \times 10^{-3}$ & $1.47 \times 10^{-3}$ \\
& $h\left(\mathrm{mg}^{-1} \cdot \mathrm{min}^{-1}\right)$ & 6.17 & 4.08 \\
& $q_{e}, \mathrm{exp}(\mathrm{mg} / \mathrm{g})$ & 48.5 & 49.2 \\
\hline
\end{tabular}

Table 3. Thermodynamic parameters for the adsorption of $\mathrm{Cu}^{2+}$ and $\mathrm{Pb}^{2+}$ onto DTD.

\begin{tabular}{cccc}
\hline Parameters & Temperature (K) & $\mathbf{C u}^{2+}$ ion & $\mathbf{P b}^{2+}$ ion \\
\hline$\Delta H\left(\mathrm{KJ}^{2} \cdot \mathrm{mol}^{-1}\right)$ & & 82.7 & 118 \\
$\Delta S\left(\mathrm{~J} \cdot \mathrm{mol}^{-1}\right)$ & & 249.4 & 356.8 \\
$\Delta G\left(\mathrm{KJ}^{-1} \mathrm{~mol}^{-1}\right)$ & 303 & 0.92119 & 1.389526 \\
& 313 & 0.450489 & 0.559536 \\
& 323 & 0.232738 & 0.325101 \\
\hline
\end{tabular}

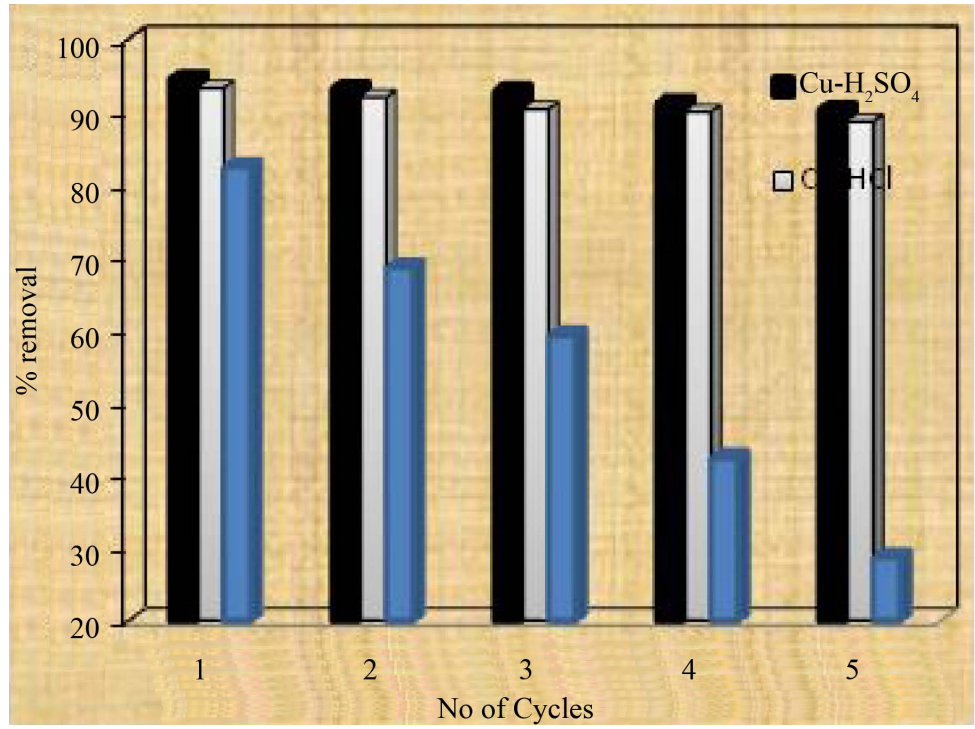

Figure 12. Adsorption-desorption cycles.

The acid solutions of $0.1 \mathrm{M}$ of $\mathrm{H}_{2} \mathrm{SO}_{4}, \mathrm{HCl}$ and $\mathrm{CH}_{3} \mathrm{COOH}$ were used as eluents. On comparison $0.1 \mathrm{M}$ solutions of $\mathrm{H}_{2} \mathrm{SO}_{4}$ and $\mathrm{HCl}$ has equal efficiency for the regeneration of $\mathrm{Cu}(\mathrm{II})$ and $\mathrm{Pb}(\mathrm{II})$ metal ions than $0.1 \mathrm{M}$ solution of $\mathrm{CH}_{3} \mathrm{COOH}$. This is due to the weak acidic nature of $\mathrm{CH}_{3} \mathrm{COOH}$. Even after five cycles of adsorptiondesorption, the efficiency of DTD did not exhibit a significant decrease. The polymeric resins with azomethine group are acid resistant and the adsorbents had a good potential for reuse. The results shows adsorption-desorption process is a reversible process which specifies the formation of coordinate bond between the chelating groups and the metals.

\subsection{Antimicrobial Activity}

The modified cellulose DTD was tested by standard disc diffusion method with E. coli, E. faecalis and S. aures and the results are presented in Table 4. The results showed that the untreated cellulose is not active against the 
Table 4. Antimicrobial activity of DTD.

\begin{tabular}{cccc}
\hline & & \multicolumn{2}{c}{ Zone of inhibition (mm) } \\
\cline { 2 - 4 } Compound & Gram negative bacteria & \multicolumn{2}{c}{ Gram positive bacteria } \\
\cline { 2 - 4 } & E. coli & E. faecalis & S. aureus \\
\hline Untreated cellulose (RA) & --- & -- & -- \\
Modified cellulose (DTD) & 8.0 & 14.2 & 12.2 \\
\hline
\end{tabular}

selected microorganisms while the modified cellulose DTD showed activity against the same microorganisms. The significant antimicrobial activity of the modified cellulose is due to the presence of methyl benzalaniline pendent groups in the cellulose chain. These new modified cellulosic materials have good antimicrobial properties and can be used in many medicinal applications.

\section{Conclusion}

Removal of $\mathrm{Pb}^{2+}, \mathrm{Cu}^{2+}$ and antimicrobial activities was carried out using novel cellulose adsorbent bearing pendent methyl benzalaniline groups (DTD). Adsorbent capacity of the chemically modified cellulose towards $\mathrm{Cu}^{2+}$ and $\mathrm{Pb}^{2+}$ is 157.3 and $153.5 \mathrm{mg} / \mathrm{g}$ respectively. The adsorbent is an active one over a wide range of $\mathrm{pH}$ values. The new modified cellulose also shows promising antibacterial activity. The adsorption kinetic studies revealed that the adsorption process fits with the pseudo-second-order model while the adsorption isotherm studies confirmed that the experimental results follow the Langmuir model. Thermodynamic studies showed that the adsorption process is feasible and exothermic in nature.

\section{References}

[1] Pagliuca, A. and Mufti, G.J. (1990) Lead Poisoning: An Age-Old Problem. British Medical Journal, 300, 830-832. http://dx.doi.org/10.1136/bmj.300.6728.830

[2] Theophanides, T. and Anastassopoulou, J. (2002) Copper and Carcinogenesis. Oncology/Haematology, 42, 57-64. http://dx.doi.org/10.1016/S1040-8428(02)00007-0

[3] Qaiser, S., Saleemi, A.R. and Umar, M. (2009) Biosorption of Lead from Aqueous Solution by Ficusreligiosa Leaves: Batch and Column Study. Journal of Hazardous Materials, 166, 998. http://dx.doi.org/10.1016/j.jhazmat.2008.12.003

[4] William O’Connell, D., Birkinshaw, C. and Francis O’Dwyer, T. (2008) Heavy Metal Adsorbents Prepared from the Modification of Cellulose. Bioresource Technology, 99, 6709-6724. http://dx.doi.org/10.1016/j.biortech.2008.01.036

[5] Low, K.S., Lee, C.K. and Mak, S.M. (2004) Sorption of Copper and Lead by Citric Acid Modified Wood. Wood Science and Technology, 38, 629-640. http://dx.doi.org/10.1007/s00226-003-0201-9

[6] Tashiro, T. and Shimura, Y. (1982) Removal of Mercuric Ions by Systems Based on Cellulose Derivatives. Journal of Applied Polymer Science, 27, 747-756. http://dx.doi.org/10.1002/app.1982.070270235

[7] Maekawa, E. and Koshijima, T. (1984) Properties of 2,3-Dicarboxy Cellulose Combined with Various Metallic Ions. Journal of Applied Polymer Science, 29, 2289-2297. http://dx.doi.org/10.1002/app.1984.070290705

[8] Navarro, R.R., Sumi, K. and Matsumura, M. (1999) Improved Metal Affinity of Chelating Adsorbents through Graft Polymerization. Water Research, 33, 2037-2044. http://dx.doi.org/10.1016/S0043-1354(98)00421-7

[9] Marchetti, M., Clement, A., Loubinoux, B. and Gerardin, P. (2000) Decontamination of Synthetic Solutions Containing Heavy Metals Using Chemically Modified Sawdusts Bearing Polyacrylic Acid Chains. Wood Science and Technology, 46, 331-333. http://dx.doi.org/10.1007/BF00766226

[10] Maekawa, E. and Koshijima, T. (1990) Preparation and Characterisation of Hydroxamic Acid Derivatives and Its Metal Complexes Derived from Cellulose. Journal of Applied Polymer Science, 40, 1601-1613. http://dx.doi.org/10.1002/app.1990.070400916

[11] Saliba, R., Gauthier, H. and Gauthier, R. (2005) Adsorption of Heavy Metal Ions on Virgin and Chemically-Modified Lignocellulosic Materials. Adsorption Science \& Technology, 23, 313-322. http://dx.doi.org/10.1260/0263617054770039

[12] Aoki, N., Fukushima, K., Kurakata, H., Sakamoto, M. and Furuhata, K. (1999) 6-Deoxy-6-mercaptocellulose and Its S-Substituted Derivatives as Sorbents for Metal Ions. Reactive and Functional Polymers, 42, 223-233. http://dx.doi.org/10.1016/S1381-5148(98)00076-5 
[13] Kelleher, B. (2001) The Development of Alternative Adsorbents for Organic Compounds in Aqueous Environments. Ph.D. Thesis, University of Limerick, Limerick, 194.

[14] Cen, L., Neoh, K. and Kang, E. (2003) Surface Functionalization Technique for Conferring Antibacterial Properties to Polymeric and Cellulosic Surfaces. Langmuir, 19, 10295-10303. http://dx.doi.org/10.1021/la035104c

[15] Abu-Laiwi, F.A., Ahmed, M.B., Ibrahim, N.A., et al. (2003) Graft Copolymerization of Methyl Methacrylate onto Rubber-Wood Fiber Using $\mathrm{H}_{2} \mathrm{O}_{2}$ and $\mathrm{Fe}^{2+}$ as an Initiator SYSTEM. Journal of Applied Polymer Science, 88, 24992503. http://dx.doi.org/10.1002/app.12107

[16] Kim, U.J., Kuga, S., Wada, M., Okano, T. and Kondo, T. (2000) Periodate Oxidation of Crystalline Cellulose. Biomacromolecules, 1, 488-492. http://dx.doi.org/10.1021/bm0000337

[17] Maekawa, E. and Koshijima, T. (1984) Properties of 2,3-Dicarboxy Cellulose Combined with Various Metallic Ions. Journal of Applied Polymer Science, 29, 2289-2297. http://dx.doi.org/10.1002/app.1984.070290705

[18] Princi, E., Vinci, S., Pedemonte, E., Gentile, G., Cocca, M. and Martuscelli, E. (2006) Synthesis and Mechanical Characterization of Cellulose Based Textiles Grafted with Acrylic Monomers. European Polymer Journal, 42, 51-60. http://dx.doi.org/10.1016/j.eurpolymj.2005.08.005

[19] Margutti, S., Vicini, S., Proietti, N., Capitani, D., Conio, G., Pedemonte, E. and Segre, A.L. (2002) Physical-Chemical Characterization of Acrylic Polymers Grafted on Cellulose. Polymer, 43, 6183-6194. http://dx.doi.org/10.1016/S0032-3861(02)00533-5

[20] El-Khoulya, A.S., Kenawy, E., Safaan, A.A., Takahashi, Y., Hafiz, Y.A., Sonomoto, K. and Zendo, T. (2011) Synthesis, Characterization and Antimicrobial Activity of Modified Cellulose-Graft-Polyacrylonitrile with Some Aromatic Aldehyde Derivatives. Carbohydrate Polymers, 83, 346-353. http://dx.doi.org/10.1016/j.carbpol.2010.07.047

[21] Langmuir, I. (1918) The Adsorption of Gases on Plane Surfaces of Glass, Mica and Platinum. Journal of the American Chemical Society, 40, 1361-1403. http://dx.doi.org/10.1021/ja02242a004

[22] Freundlich, H.M.F. (1906) Over the Adsorption in Solution. Journal of Physical Chemistry, 57, 385-470.

[23] Reddy, A.R. and Reddy, K.H. (2003) Heavy Metal Ion Uptake Properties of Polystyrene-Supported Chelating Polymer Resins. Indian Academy of Sciences, Journal of Chemical Sciences, 115, 155-160. http://dx.doi.org/10.1007/BF02704254

[24] Ho, Y.S. (2003) Removal of Copper Ions from Aqueous Solution by Tree Fern. Water Research, 37, 2323-2330. http://dx.doi.org/10.1016/S0043-1354(03)00002-2

[25] Chiron, N., Guilet, R. and Deydier, E. (2003) Adsorption of $\mathrm{Cu}(\mathrm{II})$ and $\mathrm{Pb}(\mathrm{II})$ onto a Grafted Silica: Isotherms and Kinetic Models. Water Research, 37, 3079-3086.

[26] Shukla, S.R. and Pai, R.S. (2005) Adsorption of Cu(II), Ni(II) and Zn(II) on Dye Loaded Groundnut Shells and Sawdust. Separation and Purification Technology, 43, 1-8. http://dx.doi.org/10.1016/j.seppur.2004.09.003

[27] Vengris, T., Binkiene, R. and Sveikauskaite, A. (2001) Nickel, Copper, and Zinc Removal from Waste Water by a Modified Clay Sorbent. Applied Clay Science, 18, 183-190. http://dx.doi.org/10.1016/S0169-1317(00)00036-3

[28] Chuber, N., Carvalho, J.R. and Correia, M.J.N. (2003) Cork Biomass as Biosorbent for Cu(II), Zn(II) and Ni(II). Colloids and Surfaces A: Physicochemical and Engineering Aspects, 230, 57-65. http://dx.doi.org/10.1016/j.colsurfa.2003.09.014

[29] Nie, R., Chang, X., He, Q., Hu, Z. and Li, Z. (2009) Preparation of p-tert[(dimethylamino)methyl]-calix[4]arene Functionalized Aminopropolysiloxane Resin for Selective Solid-Phase Extraction and Preconcentration of Metal Ions. Journal of Hazardous Materials, 169, 203-209. http://dx.doi.org/10.1016/j.jhazmat.2009.03.084

[30] Shukla, S.R., Pai, R.S. and Shendharkar, A.D. (2006) Adsorption of Ni(II), Zn(II) and Fe(II) on Modified Coir Fibers. Separation and Purification Technology, 47, 141-147. http://dx.doi.org/10.1016/j.seppur.2005.06.014

[31] Gupta, V.K., Rastogi, A., Saini, V.K. and Jain, N. (2006) Biosorption of Copper(II) from Aqueous Solutions by Spirogyra Species. Journal of Colloid and Interface Science, 296, 59-63. http://dx.doi.org/10.1016/j.jcis.2005.08.033

[32] Alves Gurgel, L.V. and Frederic Gil, L. (2009) Adsorption of Cu(II), Cd(II), and Pb(II) from Aqueous Single Metal Solutions by Succinylated Mercerized Cellulose Modified with Triethylenetetramine. Carbohydrate Polymers, 77, 142149. http://dx.doi.org/10.1016/j.carbpol.2008.12.014

[33] Lui, P. (2007) A Novel Degradable Adsorbent of the Hyperbranched Aliphatic Polyester Grafted Cellulose for Heavy Metal Ions. Turkish Journal of Chemistry, 31, 457-462.

[34] Aly, A.S., Sokker, H.H., Hashem, A. and Hebeish, A. (2005) Preparation of Cellulosic Membrane Containing Pyrrolidone Moiety via Radical Induced Grafting and Its Application in Wastewater Treatment. American Journal of Applied Sciences, 2, 508-513. http://dx.doi.org/10.3844/ajassp.2005.508.513

[35] Liu, P., Liu, Y. and Su, Z. (2006) Modification of Poly(hydroethyl acrylate)-Grafted Cross Linked Poly(Vinyl Chloride) Particles via Surface-Initiated Atom Radical Transfer Polymerization (SI-ATRF). Competitive of Some Heavy Metal 
Ions on Modified Polymers. Industrial and Engineering Chemistry Research, 45, 2255-2260. http://dx.doi.org/10.1021/ie051247d

[36] Lagergren, S. (1898) About the Theory of So-Called Adsorption of Soluble Substances. Kungliga Svenska Vetenskapsakademiens Handlingar, 24, 1-39.

[37] Ho, Y.S. and McKay, G. (1999) Pseudo-Second Order Model for Sorption Processes. Process Biochemistry, 34, 451465. http://dx.doi.org/10.1016/S0032-9592(98)00112-5

[38] Ho, Y.S. (2006) Review of Second-Order Models for Adsorption Systems. Journal of Hazardous Materials, 136, 681689. http://dx.doi.org/10.1016/j.jhazmat.2005.12.043

[39] Yurdakoc, M., Seki, Y., Karahan, S. and Yurdakoc, K. (2005) Boron Removal from Brine by XSC-700. Journal of Colloid and Interface Science, 286, 440-446. 